\title{
UM PANORAMA DA FORMAÇÃO CONTINUADA DE PROFESSORES DE BIOLOGIA E CIÊNCIAS ATRAVÉS DA EAD NO ESTADO DO RIO DE JANEIRO
}

\author{
Daniel Fábio Salvador | dfsalvador@yahoo.com \\ Professor Associado Doutor da Fundação CECIERJ, atual coordenador da Equipe de extensão em Biologia e coordenador do setor \\ de mídias digitais para graduação em Biologia. \\ Mirian Araújo Carlos Crapez | mirian.crapez@gmail.com \\ Professora adjunta da Universidade Federal Fluminense e vice-presidente da Fundação CECIERJ / Consórcio CEDERJ.
}

Roberta Flávia Ribeiro Rolando | eadroberta@gmail.com

Professora bolsista e coordenadora da equipe de Biologia da diretoria de Extensão da Fundação CECIERJ.

Luiz Gustavo Ribeiro Rolando | gustavoribeiro@eadmoodle.com.br

Tutor a Distância da equipe de Biologia da diretoria de Extensão da Fundação CECIERJ.

Jorge Felippe Leal Magarão | felippemagarao@gmail.com

Estudante de pedagogia da consórcio CEDERJ e Bolsista de Iniciação Ciêntífica equipe de Biologia da diretoria de Extensão da Fundação CECIERJ.

\section{Resumo}

O objetivo do artigo é apresentar o perfil dos professores que buscam por formação continuada a distância na área de Biologia da Fundação CECIERJ e a evolução dos níveis de participação deles durante o desenvolvimento dos cursos entre os anos de 2006 a 2009. Nesse período os ambientes virtuais de aprendizagem sofreram constantes inovações pedagógicas e a implementação de novas ferramentas de interação, o que refletiu positivamente na participação dos cursistas. A análise do perfil dos cursistas foi realizada a partir do mapeamento dos dados cadastrais dos inscritos nos cursos de formação continuada na área de Biologia em 2008 e 2009. Neste período, foram oferecidos oito cursos para 18 turmas, havendo um total de 6.993 pedidos de inscrição. As inscrições eram de licenciados na área Ciências da Vida em $73 \%$ dos pedidos. A maior parte dos professores que solicitaram inscrição (48\%) declarou não lecionar, com 35\% declarando trabalhar em escolas públicas de Ensino Fundamental e Médio. É importante assinalar que os licenciandos já ocupam $10 \%$ da demanda, provavelmente preocupados com a inserção no mercado de trabalho através de concursos públicos. Além desses, professores com formação na área de Humanas e os que ministram aulas em escolas particulares também têm buscado a formação continuada através da EAD. Para avaliação dos níveis de participação, foi usado o banco de dados do sistema acadêmico entre os anos de 2006 a 2009, sendo os cursistas separados em diferentes grupos: observadores, participantes, concluintes e aprovados. Houve aumento da procura por cursos de formação continuada em Biologia e Ciências, bem como maior índice de participação efetiva dos cursistas do ano de 2006 para 2009 , como a maior evolução do ano de 2008 para 2009. Entre 2008 e 2009, houve aumento significativo dos alunos participantes, concluintes e aprovados, com queda de $14,1 \%$ da taxa de evasão. Conclui-se que as novas práticas pedagógicas e ferramentas tecnológicas utilizadas têm sido de grande ajuda para os professores-cursistas na construção de novos conhecimentos e o desenvolvimento de potencialidades de aprendizagem para a promoção do crescimento profissional da docência na área de Biologia e Ciências no estado do Rio de Janeiro.

\section{Palavras-chave}

Formação continuada de professores. Ensino de Biologia. Ensino de Ciências. Educação a Distância. Ambiente virtual de aprendizado. 
AN OVERVIEW OF THE CONTINUING TRAINING OF BIOLOGY AND SCIENCE TEACHERS THROUGH DISTANCE EDUCATION IN RIO DE JANEIRO STATE

\section{Abstract}

This article aims to present a profile of teachers seeking continuing training by distance education in biology at the CECIERJ Foundation and the changes in their levels of participation in courses from 2006 to 2009. In this period the virtual learning environment underwent continuous pedagogical innovation and implementation of new interactive tools, which reflected positively on student participation. Profile analysis of students was made from registration data of those enrolled in the continuing training courses in biology in 2008 and 2009. In that period eight courses were offered to 18 groups, totaling 6993 registration applications. Seventy-three percent of applications corresponded to Life Sciences graduates. Most teachers who applied (48\%) stated that they were not teaching, while $35 \%$ stated that they worked in public schools at the elementary and high school levels. It is important to note that graduates accounted for $10 \%$ of the demand, probably concerned with joining the work market via civil service selection exams. In addition, teachers trained in the social sciences and those teaching in private schools have sought to continue their education through distance learning. To assess participation levels, the 2006 - 2009 academic system database was used, and the students placed in different groups: observers, participants, graduating and approved. There was an increased demand for continuing education courses in biology and science, as well as a higher rate of actual student participation from 2006 to 2009, and greater progress from 2008 to 2009 . Between 2008 and 2009, there was a significant increase in participating, graduating and approved students, with a $14.1 \%$ decrease in dropout rates. We conclude that the new teaching practices and technological tools used have been of great help to teachers attending the courses in acquiring new knowledge and in developing learning capabilities to promote the professional growth of biology and science teachers in the state of Rio de Janeiro.

\section{Keywords}

Continuing teacher training. Biology teaching. Science teaching. Distance education. Virtual learning environment.

\section{Introdução}

As constantes inovações tecnológicas, principalmente no que diz respeito ao uso de computadores e internet, têm influenciado modificações em várias áreas da vida moderna. Na educação não é diferente. A relação entre educação e tecnologia tem se estabelecido como recurso eficaz na formação continuada de professores, na modalidade Educação a Distância (EAD).

Inúmeras iniciativas têm acontecido no intuito de aplicar as novas tecnologias disponíveis, para tornar métodos e processos de ensino-aprendizagem mais eficazes. Neste contexto, a criação de ambientes virtuais de aprendizagem, desenhados para motivar $e$ atender as necessidades dos alunos é uma importante ferramenta em todos os níveis educacionais.

O objetivo do artigo é apresentar o perfil dos professores que buscam por formação continuada a distância na área de Biologia da Fundação CECIERJ e a evolução dos níveis de participação deles durante o desenvolvimento dos cursos entre os anos de 2006 a 2009.

\section{Fundamentação teórica}

\subsection{A formação continuada de professores através da EAD}

A necessidade de formação continuada de professores tem sido enfatizada ao longo das últimas décadas por diversos autores (Vilarinho; Sande, 2003) e pelo poder público, que nos níveis federal, estadual e municipal têm desenvolvido programas de formação continuada de professores. Como exemplo, podemos citar o Pró-Letramento e o Gestar II, que são programas do governo federal.

Sabbatini (2004) cita:

[...] sem os conhecimentos e habilidades necessárias para efetuar estes novos objetivos e estratégias, o professorado não será capaz de operar eficazmente nos cursos. Sua formação e capacitação devem ter a mesma base pedagógica que os estudantes, para uma compreensão ampla da ciência como empresa social e humana, e esta deve manter-se ao longo da carreira profissional. 
Mais do que nunca, essa necessidade fica evidente ao percebermos o momento histórico em que estamos inseridos. Estamos vivendo na era da informação $e$ da sociedade do conhecimento, onde a velocidade em que o conhecimento é gerado e compartilhado através das novas tecnologias torna crescentes as exigências e os desafios impostos ao professor (AOKI, 2004). Esta nova fase da humanidade tem quebrado os padrões de tempo e espaço, criando novos modelos de ensino-aprendizagem. Nesse contexto, ensinar e aprender deixam de ter um caráter meramente instrutivo, de transmissão do conhecimento adquirido pelo professor em sua formação inicial. O papel do professor, ao lidar com alunos em formação, se torna muito mais uma via de mão dupla, uma interação à busca de construir e compartilhar o conhecimento de forma coletiva (LUZ e FLEMMING, 2003). Diante desta realidade, a formação continuada se torna parte essencial da vida profissional dos professores. Entendemos que ela, além de corrigir falhas e preencher lacunas provenientes da formação inicial, se torna o meio pelo qual o professor poderá se manter atualizado, em face da constante evolução do conhecimento.

A regulamentação da Educação a Distância pela Lei de Diretrizes e Bases da Educação (Lei no 9.394, de 20 de dezembro de 1996) contribuiu e impulsionou os programas de formação continuada de professores. A EAD vem proporcionado a democratização de acesso à formação continuada de um grande contigente de professores em todo o país, principalmente aqueles que fazem parte do serviço público. Além do incentivo governamental, é importante ressaltar a busca pela formação continuada, por vontade exclusiva do professor, acessando os cursos de extensão da Fundação CECIERJ.

\subsection{Novos paradigmas para o ensino de Biologia e Ciências}

Nos últimos anos, o ensino de Ciências passou por inúmeras propostas de transformação. Até os anos 1960, o ensino de Ciências passou por uma longa fase em que a ciência era apresentada como neutra e o importante eram os aspectos lógicos da aprendizagem, $e$ a qualidade dos cursos era definida pela quantidade de conteúdos conceituais transmitidos. Nos anos seguintes valorizou-se a participação do aluno no processo de aprendizagem do método científico através de atividades práticas de laboratório. Na década de 1970, a crise econômica mundial e os problemas relacionados com o desenvolvimento tecnológico fizeram surgir no ensino de Ciências um movimento pedagógico que ficou conhecido como "ciência, tecnologia e sociedade" (CTS). Essa tendência no ensino é importante até os dias de hoje, pois leva em conta a estreita relação da ciência com a tecnologia e a sociedade, aspectos que não podem ser excluídos de um ensino que visa formar cidadãos. Nos anos 1980, a atenção passou a ser dada ao processo de construção do conhecimento científico pelo aluno. Inúmeras pesquisas foram realizadas nesse campo e o modelo de aprendizagem por mudanças conceituais, núcleo de diferentes correntes construtivistas, é hoje bem aceito pela maioria dos pesquisadores. Porém, os Parâmetros Curriculares Nacionais (PCN) apontam críticas a esse modelo e enfatizam a necessidade de reorientar as investigações para além das preconcepções dos alunos e considerar que a construção do conhecimento científico tem exigências relativas a valores humanos, à construção de uma visão de Ciência e suas relações com a Tecnologia e a Sociedade (PCN, 2000).

Segundo os PCN, são procedimentos fundamentais, em Ciências Naturais, aqueles que permitem a investigação, a comunicação e o debate de fatos e ideias. A observação, a experimentação, a comparação, o estabelecimento de relações entre fatos ou fenômenos e ideias, a leitura e a escrita de textos informativos, a organização de informações através de desenhos, tabelas, gráficos, esquemas e textos, a proposição de suposições, o confronto entre suposições e entre elas $e$ os dados obtidos por investigação, a proposição $e$ a solução de problemas são diferentes procedimentos que possibilitam a aprendizagem. Os conteúdos não devem ser tratados como assuntos isolados e sim em blocos temáticos, que permitam tratar conteúdos de importância local e fazer conexão entre conteúdos dos diferentes blocos, áreas e temas transversais.

Tanto para o Ensino Fundamental quanto para o Ensino Médio, os PCN enfatizam a necessidade da inte- 
gração dos conteúdos de um mesmo tema ou de áreas diferentes. Assim, o corpo humano deve ser entendido como um todo integrado que interage com o ambiente e que reflete a história de vida do indivíduo. Da mesma forma, o funcionamento do corpo e a descrição de características das doenças devem ser articulados para possibilitarem a aprendizagem efetiva e transformadora de atitudes e hábitos de vida. Doenças decorrentes de poluição, bomba atômica, fome e buraco na camada de ozônio devem ser temas abordados para promoção da saúde e também para preservação do meio ambiente.

É muito claro que o ensino de Biologia precisa ser voltado para a criação de estímulo ao aprendizado autônomo e investigativo, onde a Ciência torna-se instigante e surpreendente, em vez de conceitos estáticos e meramente memorizados. Como parte de todas as orientações pedagógicas atualmente vigentes, a contextualização e interdisciplinaridade são os carros chefes e devem ser enfocadas, bem como a construção do conhecimento do concreto para o abstrato, também é fundamental para um aprendizado eficiente.

Se analisarmos os parâmetros e orientações que balizam a educação básica no país podemos tirar algumas conclusões importantes para o trabalho de atualização de professores de Ciência e Biologia. Sobre capacitação de professores de Biologia as orientações curriculares para o Ensino Médio, MEC (2006), cita:

"Para isso, é fundamental que o professor seja capacitado, recebendo as orientações e condições necessárias a uma mudança na forma de ensinar Biologia, de maneira a organizar suas práticas pedagógicas de acordo com as concepções para o ensino da Biologia, tendo como referência os PCN. Essa capacitação deverá possibilitar ao professor reconhecer que a mudança de sua ação depende de uma educação contínua, por meio de simpósios, encontros, cursos de aperfeiçoamento que possibilitem a construção coletiva de novas alternativas educativas e permitam, também, que o professor se aproprie da cultura científica."

Segundo Shulman (1987), os professores vivenciam situações complexas na sala de aula e para isso, precisam de uma base de conhecimento, que sustente os processos de tomada de decisão. Essa base de conhecimento é constituída por um conjunto de compreen- sões, conhecimentos, habilidades e disposições necessárias para atuação efetiva em situações específicas de ensino e aprendizagem.

Entretanto, essa base não pode privilegiar ora uma elaboração cuidadosa e articulada do conteúdo a ser aprendido, ora uma metodologia atenta exclusivamente ao desenvolvimento psicológico do estudante. $\mathrm{O}$ recente crescimento de uma visão construtivista de ensino e aprendizagem recoloca o problema da formação do professor, ressaltando a importância do seu conhecimento científico e da natureza de sua competência profissional (STRIKE; POSNER, 1992). Há também que se ressaltar que, atualmente, o professor deixou de ser o único detentor e reprodutor do conhecimento para se transformar em um facilitador e/ ou coordenador de atividades, responsável por criar motivações para que os estudantes façam suas próprias descobertas no processo coletivo de construção do conhecimento. As diferentes formas de comunicação e interação das tecnologias emergentes propiciaram que a educação online participasse deste contexto evolutivo, caracterizada por Moran (2003) como "um conjunto de ações de ensino-aprendizagem desenvolvidas por meios telemáticos, como a Internet, a videoconferência e a teleconferência".

\section{Contexto do estudo}

O Centro de Ciências e Educação Superior a Distância do Estado do Rio de Janeiro - Fundação CECIERJ, órgão da Secretaria de Estado de Ciência, Tecnologia e Inovação do Estado do Rio de Janeiro, foi criado com o principal objetivo de viabilizar o acesso ao Ensino Superior da população residente no interior do estado. O Consórcio CEDERJ reúne as seis universidades públicas sediadas no estado: Universidade do Estado do Rio de Janeiro, Universidade Estadual do Norte Fluminense Darcy Ribeiro, Universidade Federal do Estado do Rio de Janeiro, Universidade Federal do Rio de Janeiro, Universidade Federal Fluminense, Universidade Federal Rural do Rio de Janeiro. Também participam ativamente desse esforço as Prefeituras Municipais, que sediam os 34 polos regionais do CEDERJ.

Através da tríade cursos de graduação, extensão e divulgação científica, a Fundação CECIERJ acredi- 
ta que o investimento na formação de profissionais competentes e autônomos é o caminho mais seguro e eficaz para a melhoria do Sistema Público de Educação Básica do Estado.

Os cursos de extensão da Fundação CECIERJ são oferecidos na modalidade de Educação a Distância (EAD) semipresencial, tendo parte das atividades realizadas na plataforma de e-Learning Moodle. O objetivo desses cursos é a capacitação de professores da rede pública no interior do Estado do Rio de Janeiro, contribuindo para a melhoria do ensino e promovendo a interação entre a Fundação e a sociedade, na construção de um projeto de enfrentamento das profundas desigualdades sociais surgidas ao longo da história brasileira.

As atividades de extensão da Fundação CECIERJ vêm sendo desenvolvidas desde o último trimestre de 2000 através da Revista de Educação Pública (www.educacaopublica.rj.gov.br). Nesse espaço virtual, os educadores têm acesso livre e gratuito a minicursos e oficinas, cursos semipresenciais, fóruns de discussão, divulgação e produção de textos educativos e científicos, além de material de suporte para a elaboração das aulas e utilização de laboratórios e recursos tecnológicos pelos professores. A partir do ano de 2003 passaram a fazer parte do conjunto de atividades de extensão cursos de atualização certificados pela Fundação CECIERJ.

A área de extensão em Biologia conta, atualmente, com seis oficinas experimentais de livre acesso online e nove cursos/disciplinas com certificação. As disciplinas são oferecidas na modalidade "semipresencial" de EAD pela internet, com as atividades a distância (AD) desenvolvidas no decorrer do curso e uma avaliação presencial (AP) ao final. Cada disciplina tem carga horária de 30 horas; elas são gratuitas e oferecidas em trimestres, com inscrições via internet. Para um relacionamento mais interativo e pessoal com o aprendiz, utiliza-se o sistema individual de tutoria a distância, com cada tutor atendendo em média 30 a 40 alunos, orientando-os durante todo o período do curso.

\section{Metodologia}

\subsection{Perfil dos alunos inscritos}

A análise do perfil dos cursistas foi realizada a partir do mapeamento dos dados cadastrais dos pedidos de inscrição nos cursos de formação continuada na área de Biologia nos anos de 2008 e 2009. Foi utilizado o banco de dados do registro acadêmico tendo sido escolhidos os seguintes itens para análise: distribuição de inscrição por região do estado do Rio de Janeiro, a rede escolar em que atua, disciplina(s) que leciona e a formação acadêmica.

No período foram oferecidos oito cursos para 18 turmas, com um total de 6.993 pedidos de inscrição. Entretanto é permitido que cada professor cursista faça até dois cursos por trimestre, sendo que dessa forma o quantitativo de professores trabalhados era menor que o número cursistas. Os dados do terceiro trimestre de 2009 não foram incluídos nessa avaliação, pois ainda não estavam disponíveis no momento da coleta e do processamento de dados deste artigo.

\subsection{Avaliação da participação dos cursistas}

A fim de avaliar a evolução dos índices de participação dos cursistas, foram adotados os seguintes critérios de diferenciação de níveis de participação durante o curso: observadores, participantes, concluintes e aprovados. Os observadores foram os alunos que tiveram a inscrição confirmada, contudo não realizaram atividades no desenvolvimento do curso. Os participantes tiveram a inscrição confirmada, realizaram algumas atividades e evadiram-se no decorrer do curso. Tresman (2002) afirma que não se pode tratar sob o mesmo título de desistente os estudantes que não completam o curso $e$ os estudantes que se matriculam mas nem começam o mesmo. Dessa forma, pode-se diferenciar o desistente do que abandonou o curso, pois o desistente inicia as atividades do curso e o que abandona apenas faz sua inscrição e não realiza nenhuma atividade. Os concluintes também tiveram a inscrição confirmada, realizaram as atividades propostas durante o curso, realizaram as avaliações a distância e presencial e foram classificados em aprovados e reprovados.

Foram utilizados os dados de participação dos cursistas cadastrados no sistema acadêmico da Diretoria de Extensão da Fundação CECIERJ entre os anos de 2006 a 2009, quando 48 disciplinas foram oferecidas tendo-se um total de 14.931 pedidos de inscrição. Entretanto somente 7.706 cursistas foram aceitos e iniciaram o curso (Tabela 1), sendo os dados calculados baseado nesse ultimo número. 
Os dados de frequência, participação e aprovação dos alunos foram comparados utilizando-se o teste estatístico qui-quadrado $\left(\mathrm{X}^{2}\right)$, que é utilizado para comparações de frequências (SAMPAIO, 1998; REA \& PARKER, 2000).

\section{Resultados e discussão}

\subsection{Perfil dos alunos inscritos}

De um total de 6.993 solicitações de inscrição nos cursos de atualização em Biologia nos três trimestres de 2008 e nos dois primeiros trimestres de 2009, 3.906 foram aceitas, devido à limitação do número de tutores para atendimento, e 2.780 alunos confirmaram a inscrição e foram incluídos na sala de aula (Figura 1).

A distribuição dos pedidos de inscrição em 2008 e 2009 mostra aumento crescente, ressaltando que os professores do Ensino Médio do estado têm procurado cada vez mais a formação continuada em Ciências e Biologia (Figura 1). Esse fato fica mais evidente se observados os números de pedidos de inscrição desde o ano de 2006 a 2009 (Tabela 1).

Figura 1: Número de alunos inscritos, aceitos e confirmados entre 2008 e 2009.

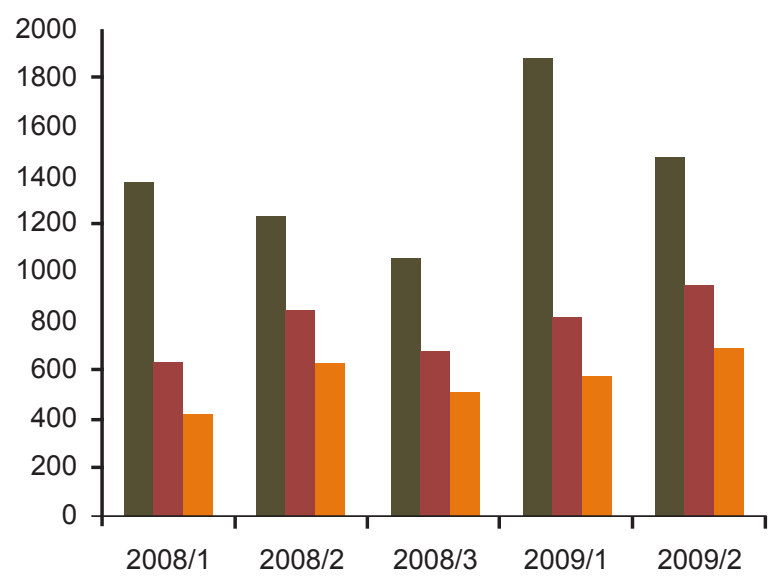

Alunos inscritos

Alunos aceitos

Alunos confirmados

Figura 2: Área de formação profissional dos alunos entre 2008 e 2009.

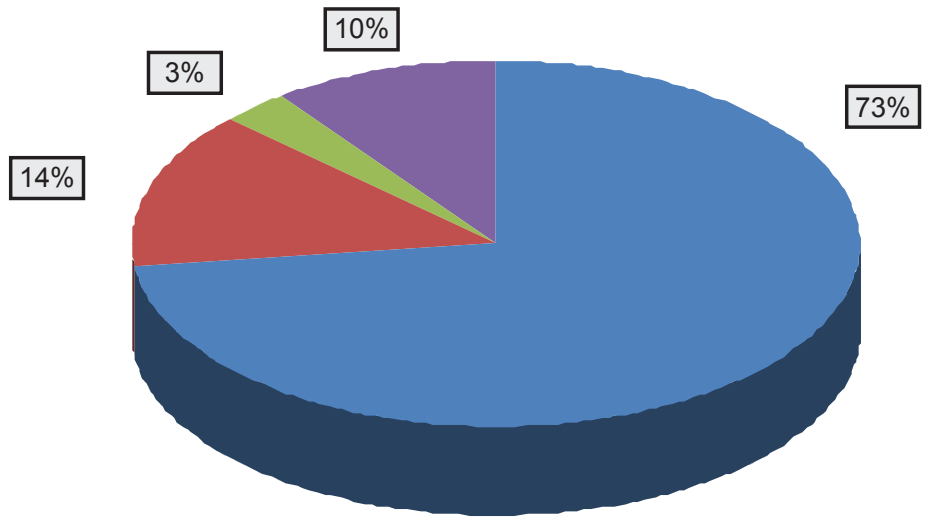

Ciências da Vida

Ciências Humanas

Ciências Exatas

Outras

A fim de conhecer o perfil daqueles que buscam os cursos de atualização de professores em Biologia no estado do Rio de Janeiro na modalidade $\mathrm{EAD}$, foram analisadas as informações declaradas pelos cursistas no momento da inscrição em 2008 e nos dois primeiros trimestres de 2009.

O maior percentual de inscritos foi de profissionais da área de Ciências da Vida com $73 \%$ de inscrição, seguida pela área de Ciências Humanas, com 14\% (Figura 2).

Do total de pedidos de inscrição, $98 \%$ dos alunos têm formação completa de terceiro grau. Destes, $73 \%$ são professores com licenciatura plena, havendo, entretanto, um razoável percentual de profissionais com bacharelado (13\%). Os licenciandos constituem $10 \%$ do total de inscritos, mostrando o potencial dos cursos de formação continuada para atualização e enriquecimento pessoal (Figura 3).

Verificando o perfil desse público em relação ao local onde leciona, há uma distribuição de $35 \%$ dos pedidos de inscrição provenientes de pessoas que declararam estar atuando em escolas públicas, $17 \%$ em escolas 
particulares e $48 \%$ não lecionavam no momento da inscrição (Figura 4). Esses últimos são na maioria professores buscando qualificação para o seu primeiro emprego como professor ou atualização para recolocação no mercado, no caso de professores que deixaram de exercer a profissão por um tempo. Em estudo realizado no período de 2006 e 2007 com o mesmo público-alvo, o maior índice de alunos inscritos ocorreu também entre professores da rede pública (42\%), sendo que $53 \%$ lecionavam (SALVADOR et al., 2008).

Figura 3: Perfil acadêmico dos alunos inscritos entre 2008 e 2009.

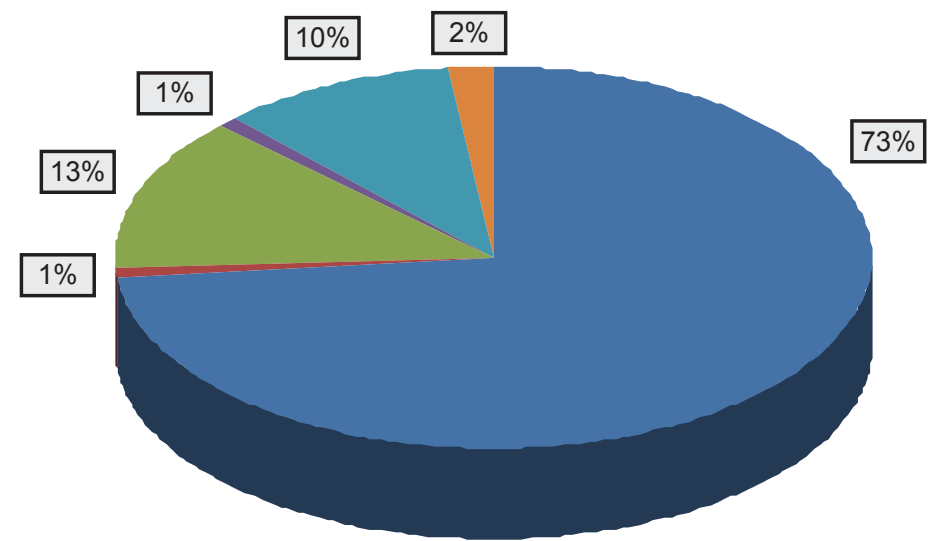

Licenciatura plena

Licenciatura plena

Bacharel

Tecnólogo

Licenciado

Não possuem
Em relação ao perfil acadêmico, $73 \%$ dos pedidos de inscrição eram de professores com licenciatura plena. É importante assinalar que os licenciandos já ocupam $10 \%$ da demanda, provavelmente preocupados com a inserção no mer- cado de trabalho através de concursos públicos. Além destes, professores com formação na área de humanas e os que ministram aulas em escolas particulares também têm buscado a formação continuada através da EAD.

Figura 4: Local de trabalho dos alunos inscritos entre 2008 e 2009.

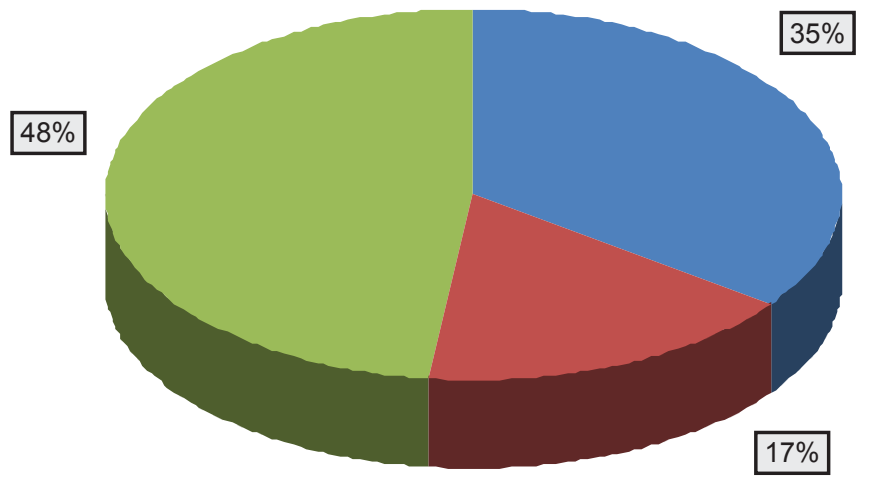

Escola pública

Escola particular

Não lecionam
O perfil dos cursistas em relação às disciplinas que ministram aula mostrou percentual semelhante entre o ensino de Biologia (Ensino Médio) e Ciências (Ensino Fundamental) (Figura 5). O alto percentual que de-

Figura 5: Principais disciplinas ministradas pelos alunos entre 2008 e 2009.

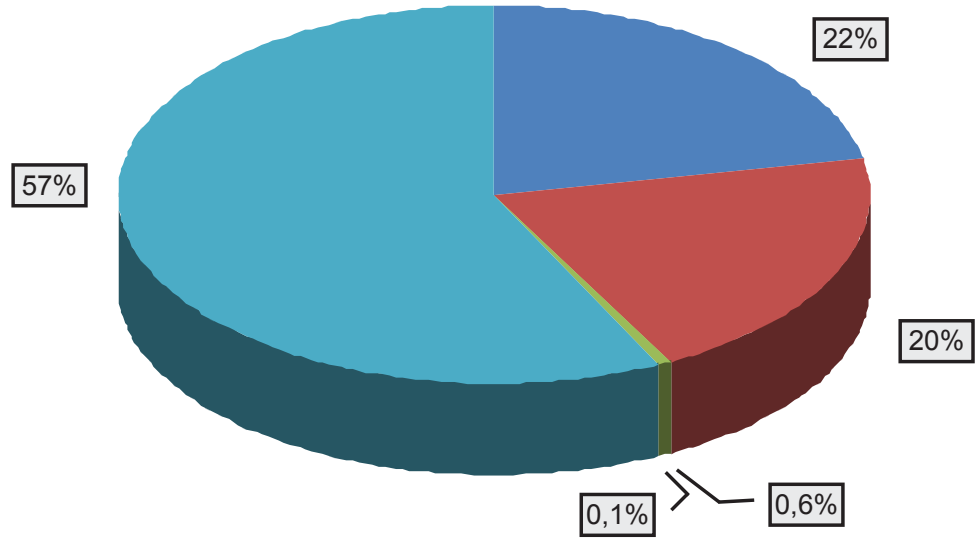

\begin{tabular}{|l|}
\hline Biologia \\
Ciências \\
Química \\
Física \\
Outras \\
\hline
\end{tabular}


clarou "outras" nos formulários, provavelmente, pode ser explicado pelos alunos que não lecionam, conforme observado na Figura 4.

\subsection{Evolução da participação dos cursistas entre 2006 e 2009}

Na Tabela 1 são apresentados os resultados de total de turmas oferecidas, pedidos de inscrição $e$ total de alunos que iniciaram os cursos de forma- ção continuada de professores da área de Biologia da Diretoria de Extensão nos anos de 2006, 2007, 2008 e 2009.

A comparação entre os anos mostrou que o número total de pedidos de inscrição aumentou (Tabela 1), com o quantitativo de 2009 sendo mais que o dobro de 2006. O número de alunos observadores decaiu de 60,1\% em 2006 para 50,9\% em 2008, com a diminuição mais expressiva em 2009, quando chegou a

Tabela 1: Número de cursos oferecidos, pedidos de inscrição e alunos que iniciaram os cursos entre o ano de 2006 a 2009

\begin{tabular}{c|c|c|c}
\hline Ano & Turmas oferecidas & Pedidos de inscrição & $\begin{array}{c}\text { Alunos que iniciaram } \\
\text { o curso }\end{array}$ \\
\hline 2006 & 12 & 2138 & 1943 \\
\hline 2007 & 15 & 3996 & 2485 \\
\hline 2008 & 9 & 3650 & 1538 \\
\hline 2009 & 12 & 5147 & 1740 \\
\hline Total & 48 & 14931 & 7706 \\
\hline
\end{tabular}

Tabela 2: Percentual de participação dos alunos de 2006 a 2009

\begin{tabular}{|c|c|c|c|c|}
\hline \multirow{2}{*}{ Categoria } & \multicolumn{4}{|c|}{$\%$} \\
\hline & 2006 & 2007 & 2008 & 2009 \\
\hline Observadores & $60,1 a$ & $54,7 \mathrm{~b}$ & $50,9 c$ & $24,6 d$ \\
\hline Participantes & $39,9 a$ & $45,3 b$ & $49,1 \mathrm{c}$ & $75,4 d$ \\
\hline $\begin{array}{c}\text { Concluintes em relação } \\
\text { aos participantes }\end{array}$ & $46,1 a$ & $47,0 a b$ & $49,8 a b$ & $51,6 b$ \\
\hline Evasão efetiva & $53,9 a$ & $53,0 a b$ & $50,2 a b$ & $48,4 b$ \\
\hline $\begin{array}{c}\text { Concluintes em relação } \\
\text { aos que iniciaram }\end{array}$ & $18,4 a$ & $21,3 b$ & $24,4 \mathrm{c}$ & $38,8 d$ \\
\hline Evasão total & $81,6 a$ & $78,7 \mathrm{~b}$ & $75,8 \mathrm{c}$ & $61,2 d$ \\
\hline
\end{tabular}

Obs.: Letras diferentes $(\mathrm{a}, \mathrm{b}, \mathrm{c}, \mathrm{d})$ na mesma linha representam diferença estatística $(\mathrm{p}<0,05)$ pelo teste de Teste $\mathrm{X}^{2}$.

24,6\%. Como consequência, o número de alunos que se tornaram participantes atingiu $75,4 \%$ dos inscritos no curso. O aumento de alunos participantes propiciou no ano de 2009 um maior número de concluintes (39\%), com o percentual de evasão caindo de $81,6 \%$ para $61,2 \%(p<0,05)$.

A evasão efetiva (desistente em relação ao participante) para os anos de 2008 e 2009 foi calculada em 50,2 e 48,4\%, respectivamente, não havendo diferença significativa entre esses índices. Entretanto, se observarmos a evasão total (desistente em relação ao que iniciaram o curso), esta apresenta diminuição de $14,6 \%$ ( $p<0,05)$, uma vez que o principal reflexo das novas ações pedagógicas e ferramentas foi elevar $\mathrm{o}$ número de cursistas participantes nas turmas.

Para explicar essa evolução dos percentuais com o passar dos anos, sabemos que no ano de 2006 os cursos eram realizados de forma pouco interativa, com o material didático distribuído para os estudantes em um sítio HTML $e$ as atividades eram 
enviadas por e-mail aos tutores, para correção. A plataforma servia somente para distribuição de material e para comunicação geral dos professores com os cursistas.

A partir de 2007, o material didático passou a utilizar objetos midiáticos animados e atividades a distância contextualizadas com tutoria individualizada, com criação do ciclo de ação-reflexão em atividades específicas, promovendo mais diálogo e interação entre cursistas e tutores.

Entretanto, Salvador et al. (2008) mostraram que, entre 2006 e 2007, os percentuais para os perfis dos alunos foram semelhantes, com evolução contínua da diminuição do número de observadores, porém sem efeito em relação à taxa de evasão.

Já em 2008 e mais acentuadamente 2009 houve aumento significativo dos alunos participantes, concluintes e aprovados. De forma geral, a proposta metodológica a partir de 2008 era construir os cursos baseados em textos principais e complementares, animações, vídeos, sites para pesquisa na web e atividades a distância contextualizadas. Além disso, os alunos eram acompanhados por tutores no ambiente virtual de aprendizagem, na proporção de 1:50 alunos ativos. A ferramenta "fórum" foi utilizada para discussões, criações coletivas e colaborativas entre os alunos, tutores e professor do curso, fazendo parte da atividade a distância (AD), que compunha $40 \%$ da nota final no curso. Os outros $60 \%$ da nota eram avaliados através da prova presencial final, realizada ao final da disciplina.
A partir do terceiro trimestre de 2008 os cursos passaram a utilizar novas ferramentas de comunicação, colaboração e interação através de um ambiente de aprendizado mais atrativo $e$ intuitivo.

\section{Conclusão}

O perfil dos cursistas inscritos mostrou que as inscrições eram de licenciados na área Ciências da Vida em $73 \%$ dos pedidos. A maior parte dos professores que solicitaram inscrição (48\%) declarou não lecionar, com $35 \%$ declarando trabalhar em escolas públicas de Ensino Fundamental e Médio.

Quanto à evolução dos índices de participação dos cursistas que iniciam o curso, os dados mostram aumento anual do número de pedidos de inscrição e aumento significativo dos alunos participantes, concluintes $e$ aprovados em 2008 e mais acentuadamente em 2009.

A justificativa de evolução dos índices de participação está relacionada às mudanças implementadas nos ambientes dos cursos: planejamento pedagógico flexível e adaptado à realidade cognitiva dos cursistas; aulas virtuais interativas; produção de objetos de aprendizagem multimidiáticos; atividades a distância contextualizadas; acompanhamento individual por "tutoria a distância" através da internet; incentivo à aprendizagem colaborativa através de novas ferramentas da internet.

Além dessa evolução numérica, acreditamos que a aplicação de tais princípios e ações tem tornado possível a construção de novos conhecimentos e o desenvolvimento de potencialidades de aprendizagem para a promoção do crescimento profissional da docência na área. 


\section{Referências bibliográficas:}

AOKI, J. M. N. As tecnologias de informação e comunicação na formação continuada dos professores. Educere.Umuarama. v. 4, n. 1, p.43-54, 2004.

BRASIL. Ministério da Educação. Secretaria da Educação Básica. Orientações curriculares para o ensino médio: ciências da natureza, matemática e suas tecnologias. Brasilia, DF: Ministério da Educação, 2006. v. 2.

BRASIL. Lei 9394 - LDB - Lei das Diretrizes e Bases da Educação, de 20 de dezembro de 1996.

BRASIL. Ciências da Natureza, Matemática e suas Tecnologias: Parâmetros Curriculares Nacionais Ensino Médio. Brasília: MEC/SEMTEC, 2000.

GATTI, B.A. Análise das políticas públicas para formação continuada no Brasil, na última década. Revista Brasileira de Educação v. 13 n. 37 jan./abr. P. 57-186, 2008

LUZ, E. F. ; FLEMMING, D. M. . Formação Continuada de Professores de Matemática Usando Ambiente Virtual de Aprendizagem. In: 11th inter-american conference on mathematics education, 2003, Blumenau. Anais da XI Conferência Interamericana de Educação Matemática. Blumenau : Furb, 2003.

MORAN, J. M. Contribuições para uma pedagogia da educação online. In: SILVA, Marco (org.). Educação online: teorias, práticas, legislação, formação corporativa. São Paulo: Loyola, p. 39-50, 2003

PALLOFF, Rena M, PRATT, Keith. Construindo Comunidades de Aprendizagem no Ciberespaço.

Alegre: Artmed, 2002.

REA, L.M. \& PARKER, R.A. Metodologia de pesquisa: do planejamento a execução. Ed. Thomson Pioneira, 2000.

SABBATINI, M. Alfabetização e cultura científica: conceitos convergentes? Ciência e Comunicação, v. 1, n. 1, 2004.
SAMPAIO, I.B.M. Estatística aplicada à experimentação animal. Belo Horizonte: FEP-MVZ, 1998.

SALVADOR, D.F. et al. A performance evaluation of Sciences and Biology teaching improvement courses using on-line distance-education, in the state of Rio de Janeiro, Brazil. 2006. In: ICDE, 22, ABED, Rio de Janeiro, 2006.

SALVADOR, D.F., PFEIFFER, C. Utilizando design instrucional baseado em aprendizagem significativa para capacitar professores em Biologia via web. In: Virtua Educa 2007, São José dos Campos, Virtua Educa, 2007.

SALVADOR, D. F., ROLANDO, R. F. R., FERNANDES, M. C. P., MORENO, E. L., ALVES, C.H.S. Desenho instrucional de cursos baseados na web para formação continuada de professores de Biologia. In: Sétima Conferencia iberoamericana em Sistemas, Cibernética e Informática, 2008, Orlando, USA. Memórias CISCI 2008. Orlando, flórida : IIIS, 2008. v. 2. p. 124-129.

SHULMAN, L. S. Knowledge and teaching: foundations of the new reform. Harvard Educational Review, v. 57, n. 1, p. 1-22, 1987.

STRIKE, K.A.; POSNER, G.J. A revisionistic theory of conceptual change. In: DUSCHL \& HAMILTON (Ed.). Philosophy os science, cognitive science and educational theory and practice. Albany, NY: SUNY,. p.147-176, 1992.

TRESMAN, S. Towards a strategy for improved student retention in programmes of open, Distance Education: A case study from open University UK. International review of research in open and distance learning. 3(1), 2002.

VILARINHO, L. R. G.; SANDE, I. C. Formação Continuada de Professores em Cursos a Distância: NovasPerspectivas doProcessoEnsino_Aprendizagem. In: $1^{\circ}$ Seminário Nacional $\mathrm{ABED}$ de Educação a Distância, 2003, Belo Horizonte. Anais do I Seminário Nacional da Associação Brasileira de Educação a Distância, 2003. v. 1. 